\title{
CAN RESEARCH BE MADE PRODUCTIVE?
}

\author{
What follows is the substance of an address by Sir Harry Melville, Secretary of the \\ Science Research Council, delivered under the title "The Organization of Science \\ in Britain" to a conference on science policy held at the proposed University of \\ Bath a week ago.
}

In the increasingly technological age in which we live, the competitive position of the United Kingdom is of concern to everyone. With a limited and fairly highly skilled population and limited access to raw materials, our striving has got to be towards higher quality in our science and technology so that industry can maintain and, if possible, increase its lead substantially over its overseas competitors. Our position might then be assured and the constant balance of payments crises to which we are increasingly subject eliminated completely. In the short term this must be done by increasing productivity with existing manpower and equipment. There is, however, a longer term policy which is my present concern. This is the training of manpower in science and technology up to the highest possible levels and the prosecution of research at a level in the universities that enables this manpower to lead in the chosen fields of study. A lead in fundamental science with a constant absorption of such trained people into industry will ensure a continued revolution in tech. nology which, given the conditions, will maintain the country's technological lead. There is continued talk of this country opting out of advanced technology of all kinds. The excuses for this move are manifold-small production units, small markets, lack of people of appropriate training, etc. The danger is that if we opt out of too many technological activities we shall take irrevocable steps to become a very third-rate nation indeed. In many cases there is no need for such a course provided we face up to the problems involved.

The financial resources needed to mount a substantial amount of university research are so large that it is inevitable it should necessarily come from central government. This is a pattern common to all advanced countries no matter what their political colour. The Science Research Council, though a large operator in this field, is not the only body concerned.

At the base of the whole scheme are the operations of the University Grants Committee, which is responsible for providing the greater part of the income of the universities-on the average, about 70 per cent. Apart from expenditure on buildings, this money is designed to cover the general operating expenses of a university, and the university is free to decide how it shall be spent and in particular how it should be apportioned between disciplines. It is, however, recognized that the grant is insufficient to support all the research that can be done by the academic staff. It is expected that the staff will also have to seek funds elsewhere. These come, of course, from charitable trusts, private and public industry and the Research Councils. Some might argue that the U.G.C. could supply all the funds that are needed. In that case the university might set up its own internal research fund and distribute it on internal advice from the staff. The alternative and more enlightened view is that it is not the best way to support research. It would mean that there was then only one source of government funds.

The budgets for the Research Councils for $1966 / 67$ are approximately $£ 70$ million, with the Science Research Council spending more than the others put together. In addition, the defence departments, the Ministry of Technology, and the Atomic Energy Authority award extra- mural contracts to universities in order that work directed to a defined line of enquiry of interest to the sponsoring department should be carried out. The sum of money involved for this exercise is somewhat over a million pounds a year. It is not easy to estimate how much of the recurrent grant from the U.G.C. is spent on seientific research and an enquiry is now in progress to try to determine this figure. Very roughly speaking it is believed that about $£ 40$ million might be spent in this fashion. It therefore falls to the lot of the S.R.C. to perform the job of supporting university research on a fairly large scale.

Our first and basic job is to support a sufficiency of postgraduate students and postdoctorate fellows because the academic staff naturally cannot devote their whole time to research and in any case their university duties inevitably mean that they cannot give the continuous attention to the prosecution of research which is so essential in some fields. The question of policy is to determine how much money and how many people should be supported for this purpose. In an honours class, for example, there is only a limited number of students capable of doing research and undergoing further training and, of course, not all these students want to do research. Of those that are capable and willing, the question is what fraction should be supported by the S.R.C. ? Going on the good principle that not all university income should come from the state, it follows that this fraction should be less than unity. Assuming therefore that the support of research students comes from a multiplicity of external sources, from the universities' own funds, from industry and other bodies, the principle we have adopted hitherto is for the S.R.C. to provide all applicants with awards provided only the qualifications of the student exceed a defined limit - a limit set by the universities themselves. This means that the university really decides who can do research and we in S.R.C. have naturally to accept that judgment. It is important therefore that this standard should be maintained particularly during the present rapid expansion period. So far, S.R.C. has been able virtually to meet these requests. 'The result is that we support half of all British science postgraduate students-at the moment about 6,000 . There are, however, many variants of the scheme for ensuring that students are properly trained during their postgraduate careers. A few years ago, for example, we introduced a scheme of advanced course studentships to enable postgraduate students to take courses of instruction either as a continuation of their undergraduate courses of study or as a means of studying a related subject so that they would bo better qualified and trained for their ultimate professional life. Experience has shown that these studentships are becoming increasingly popular.

The provision of postdoctoral fellowships is likewise well established on a very much smaller scale than that of research studentships. Here there is some controversy as to what should be the proper level. On one hand the universities are interested in having a small number of experienced people who can carry out research with only very light teaching duties, and this is particularly important in some fields of study where the apparatus, the techniques and the knowledge are highly specialized and 
skilled; without such postdoctorate fellows some kinds of research would be very difficult to carry out. On the other hand, too much of an increase in the numbers of such fellowships would make it difficult for potential employers in industry, universities and government to recruit suitably trained staff. The balance between these opposing tendencies is difficult to strike, but in the case of S.R.C. there are in fact only 250 such fellowships in existence. Such schemes can be used in a variety of ways, for example, each year the government agencies mount an intensive recruiting drive to bring back those scientists who take up the numerous postdoctorate fellowships available in the United States. Such fellowships can, of course, be held by those who come back to this country, but in order to lessen the severity of the brain drain (and this is still a serious matter) arrangements are now made to offer a departing student a fellowship on his return together with a promise that the cost of travel back to this country will also be made. Moves of this kind have been successful. A scheme of industrial fellowships has also been evolved to permit men to return to research and, what is more, to return at salaries equal to those obtaining in industry.

The distribution of these awards among the various subjects is determined by a great variety of factors, such as the demand from universities, the size of research schools, the size of honours classes. These really are factors which the universities themselves determine. Surveys of manpower requirements and the needs for particular kinds of scientists, however, pose the question as to whether the S.R.C. should take note of these requirements and so arrange the distribution of awards. This has been done to a limited extent in applied science.

The whole system of postgraduate awards is under critical review at present. Increasing disquiet has been voiced that not a large enough fraction of the best postgraduate students are finding their way into productive employment outside the universities. Since one of the objects of postgraduate training is to provide the leaders in technology, it is really important to meet industrial demand. The recent rapid expansion of the universities has, of course, drained off a large fraction of the most able people nearly permanently into the university system. In that sense the universities are in a way to blame. On the other hand, some industries do not understand how to employ the highly trained graduate effectively and consequently bitterly complain about the training he gets. There is here a great gap to be filled in getting the postgraduate to industry's needs and particularly the needs of the future. Both sides have tended to go it alone and to their mutual disadvantage. A change of orientation need not take long, for the students are going through in increasing numbers. A real understanding between universities and industry could markedly improve the position. In chemistry, for example, the long tradition of the science-based chemical industry has ensured a close link with the universities that has led to a large flow of able people into this industry. Even so, this does not mean that the postgraduate training now given is the best that could be devised to meet the prosecution of university research and also the needs of the chemical industry.

On research grants, it is the duty of the Research Councils to supplement the University Grants Committee's basic provision for research. The expenditure on these grants has risen very rapidly in response to continued demand, and has increased from $£ 0.48$ million in $1957 / 58$ to $£ 5.8$ million in $1965 / 66$. The rate of increase of these grants so awarded is much greater than the rate of increase of research students and staff and is the fastest growing part of the activity of the S.R.C.

If this rate were to continue to increase, there would be serious problems as to where the limit should be located. One of the important problems at present is to justify an increased rate which is very significantly greater than the increase in the gross national product of the country. In other words, we have to ask for an increased share of government spending in this field. Government policy, however, is to increase the numbers in the universities by quite considerable amounts, and it is expected that the increase in science graduates will amount to 7 per cent a year for a number of years to come. In addition, the complexity of modern apparatus increases significantly and at present it is thought that this percentage increase amounts to about 5 per cent so that in addition the rate of increase of funds would need to be about 12 per cent.

Increase in complexity of apparatus means more effective ways of doing science and thus an increase in productivity. If, therefore, rates of expansion were curtailed, wise investment in instrumental aids would enable the universities to maintain a healthy output of original research.

Although normally these funds are distributed widely among the universities there are other problems. It is clearly impossible to give large-scale support to all subjects in all universities-the men and also the money are simply not there. A selective approach to the support of research is becoming a necessity. This happens naturally for a variety of reasons. It does not mean a weakening of the position in any one university, but that support is given on a kind of national basis in that the position of the subject is considered within the country as a whole and that one or a few departments are selected or self-selected to develop strongly in the proposed direction. It means, too, that if postgraduate students wish to study a particular branch of a subject they will have to migrate to a suitable centre.

This mechanism of selective approach is of importance in another connexion. It can lead to the creation of special institutes for research within the university system. The staff automatically take part in the teaching programmes and of course teach advanced courses on their particular subjects. Although the traditional pattern of university dopartments tends to prevail even in new universities, there are interdepartmental fields where research should be fostered. New subjects arise which cannot conveniently be brought within the existing system. This is where earmarked research grants can initiate and maintain new developments for a number of years.

The provision of support for university research within the university is only part of the whole picture. In some subjects, especially physics, the installations are so big that no university could and would be willing to manage them. These installations are absolutely necessary if some kinds of science are going to advance. Quite serious problems thus arise which ultimately mean drastic modification of attitudes to academic research.

In order to illustrate I should like to consider (a) nuclear physies, (b) space research, and (c) astronomy. The particle accelerators are the essential tools for nuclear physics. The technology of accelerating particles has rapidly advanced permitting more and more powerful machines to be constructed. Cockeroft and Walton managed with $0 \cdot 6 \mathrm{MeV}$. Now there are machines operating at $30,000 \mathrm{MeV}$, one being constructed at $70,000 \mathrm{MeV}$ and projected machines which are technically feasible at $300,000 \mathrm{MeV}$ and a device now being built to go to the equivalent of $1,700,000 \mathrm{MeV}$. For the bigger machines the cost is $£ 150$ million with operating costs at $£ 25$ million per annum. These energies do not yet approach the energy of the highest energy cosmic rays from outer space. There is therefore continued pressure to go to higher energies so that the nature of fundamental matter can be explored. Though smaller accelerators can be used in individual departments of physics and provide useful knowledge as well as providing advanced training facilities, there is no question that the work has to be done in national or international laboratories. The arrangement in Britain consists of two national laboratories-one near Harwell (Chilton) having a modest $7-\mathrm{GeV}$ proton accelerator and another just being completed in Cheshire having an 
electron accelerator at $4 \mathrm{GeV}$. Together these laboratories cost $£ 10$ million per annum to maintain. They provide equipment for high energy nuclear physies and the hope is that in their active life worthwhile results will be achieved. But they are the machines to which nuclear physicists must go if they want to experiment at these energies. This involves spending long periods planning and experiments in collaboration with the laboratory staff, then supervising the experiments and finally analysing the results. Consequently, departments have to be big enough to make it possible for these men to be absent though, of course, lecturing and other work has to be done by others. Thus the organization of a department has to be moulded in a very diffe rent way from the normal. So, selective support will increase in this field and, even though nuclear physies forms a substantial part of modern physics, research on it cannot be conducted in every department.

There are, however, more serious probloms in dealing with these most expensive installations. More than 10 years ago Europe combined to create an international facility in Geneva, where an accelerator of $30 \mathrm{GeV}$ which has been operating for 5 years exists. The problems of international collaboration in construction and in operating have also been solved, but there is only one such machine for the whole of Europe. Collaboration with British universities is even more difficult, for people have really to be seconded to the central facilities for years at a time as well as spending short periods to carry out their experimental work. The cost of such researches is high and not normally part of a university budget. This is where the Research Council Schemes have to come in to help. The next stage is really the intercontinental machine and may be up to $1,000 \mathrm{GeV}$. The political, financial and operational problems have become immense. The big groups in Europe, the United States and the U.S.S.R. are beginning to realize that, when such a situation is seriously to be considered, this problem has somehow to be overcome, for the work cannot otherwise be done.

The second item in big science is space research in the field of pure science, not communication or other kinds of satellite. The policy is again one of collaboration. A certain amount of work has been and is being successfully done by sending up sounding rockets (at $£ 7,000$ a time) to a height of about 200 miles to enable experiments to be done for only a few seconds. But this is not really satisfactory and a satellite is the only way in which a reasonable period of observation can be obtained. The construction of a satellite, including the experiments to be mounted in it, is well within Britain's financial and technological capacity and it is being done now ( $£ 1$ million is sufficient for one), but the launching of it is quite another matter and can cost as much again.

Britain is therefore in science in space in a modest but effective way. The United States recognizes the quality of the work and is willing to fly our experiments alongside their own. Though the science and technology of launching is denied to us, at any rate we do not exist in a state of inexperience and ignorance of what is possible in space science. Whether this will be of value, say, in satellite communications is not known.

In astronomy, both optical and radio, the position is once again quite different except that the instruments needed for the next generation of telescopes can cost many millions, and this compares with accelerators, though their cost of operation is much more modest. Fortunately, radio telescopes can operate under any weather conditions (except high winds) and can be located in this country. They must, however, be located in regions which are electrically quiet and thus away from most universities. Optical observatories even moro have to be located in suitable regions, and now, particularly in the southern hemisphere, astronomers have long been accustomed to working under such conditions and the position is already solved.
The final and most important question is: Why do it at all, particularly when there is every prospect that cost will mount very rapidly in the course of the next few years? The first part of the answer is that postgraduate students can be effectively trained to higher levels by doing research under supervision of experienced people. This wider experience at the very least can add to our national potential. Both in science-based industries, which are the biggest employers of scientific manpower, and in the more traditional industries it is the more highly trained men who should be the innovators. The second and not less important reason is that university staff must have the opportunity to keep themselves at the forefront of scientific knowledge by their active participation in research. If this is not done in the universities there is no question that the whole level of scientific work in industry, and in government, too, would fall to such a low level that Britain would become a very inferior country indeed.

If we accept this position, however, the next problem is whether there should be a conscious effort to guide the pattern of this very considerable operation. Traditionally the universities alone know what they want to do and expect financial support to do it. On the other hand, students are going to enter those fields for which their training fits them--mainly in industry, in government central and local and in teaching in universities, colleges and schools. Thus the effort in various subjects is controlled ultimately by the jobs available. If attempts were made to alter the pattern by central guidance from government, then there is the prospect of graduate/job relationships breaking down seriously. However, it may be desirable to attempt to alter the fraction of students going on to postgraduate study. In particular it may be desirable to produce some highly trained people because our industry' cannot maintain its competitive position without a reasonable influx of such highly trained graduates. This is true in engineering and allied applied sciences. The S.P.C. policy is to encourage more applied scientists to take higher training whether it be instruction or research. Many parts of British industry ought to employ more highly qualified people to raise their standards.

This then raises a more vexed question. Should the researches be geared to practical needs? (By this I do not mean the solution of short-term problems of industry.) Or should it be left completely free for the university staff to choose? This is a problem of the utmost delicacy. If, however, support is reasonably made available the burden of doing routine jobs is covered by the provision of highly priced automatic equipment, suitable supporting technical staff and adequate workshop facilities, there is now a tendency to make research so easy that results almost. without limit may be produced-results which do not really advance knowledge. It is of the utmost importance to provide ample support, but only to people of the highest quality and originality.

In applied science there is not the same dilemma. There, research should be geared to industrial problems, with longer-term policy in mind. Too much research in these fields has little relevance to industrial practice, and with this the students and ultimately British industry (which provides indirectly the wherewithal to support universities) suffer. Much has bcen said about fostering closer relationships between industry and the uxiversities, but both sides are extremely slow and over-cautious. In this country we simply cannot afford to do research on a large scale in the universities without having regard to its impact on the country's economy. In fact, I would go further and say that some universities enjoy such a level of support that it behoves the staff to prick their consciences occasionally to make quite sure that they are doing everything in their power to promote by their scientific activities the cconomic well-being of the country so that they can look forward to the continued health of the universities as a whole. 